\title{
AVALIAÇÃO DE AÇÕES EDUCATIVAS SOBRE CONSUMO DE DROGAS E JUVENTUDE: A PRÁXIS NO TRABALHO E NA VIDA
}

\author{
EVALUATION OF EDUCATIONAL ACTIVITIES CONCERNING DRUG ABUSE AND YOUTH: \\ PRAXIS AT WORK AND IN LIFE
}

\author{
Cássia Baldini Soares ${ }^{1}$ \\ Célia Maria Sivalli Campos ${ }^{2}$ \\ Juliana Sette Berto ${ }^{3}$ \\ Érica Gomes Pereira ${ }^{4}$
}

Resumo O objetivo deste artigo é analisar como conhecimentos sobre consumo de drogas e juventude foram incorporados às práticas sociais de participantes de oficinas para debate, sensibilização e instrumentalização de trabalhadores de instituições sociais, ocorridas há três anos. Foram realizadas 13 entrevistas, utilizando-se roteiro com questões sobre: temas discutidos e estratégias utilizadas, contribuição para o desenvolvimento pessoal e profissional, análise de situações-problema. Os resultados indicaram que os participantes desenvolvem práticas no trabalho e na vida caracterizadas por compreender a rede de causalidade imbricada no consumo de drogas, que envolve reflexões sobre mercadorização da droga, problemas decorrentes da criminalização e do mercado de trabalho. Foram também discutidos valores contemporâneos e dificuldades da família e da escola na socialização dos jovens. Nessa direção, observam-se cuidados para compor discursos que não culpabilizem os usuários. Preferir-se-ia uma atitude de compreensão e diálogo diante das situações-problema colocadas. Embora haja discursos que oscilem, entre formas hegemônicas e críticas de apreensão do problema, é possível perceber que a compreensão mais geral remete ao complexo sistema de produção, consumo e distribuição de psicoativos e à busca de soluções sociais ampliadas. As práticas sociais desenvolvidas, no entanto, evidenciaram ausência de políticas públicas para o enfrentamento do problema.

Palavras-chave avaliação de programas e projetos de saúde; educação; usuários de drogas; juventude.
Abstract The aim of this article is to analyze how knowledge about drug abuse and youth has been incorporated into the social practices of workshop participants to drive discussion and awareness, and how they have become tools for workers in social institutions over the past three years. Thirteen interviews were carried out based on a script with questions on: topics discussed and strategies used, contributions for personal and professional development, and problem situation analyses. The results show that the participants develop practices at work and in life that are characterized by their understanding of the intertwined network of causality in drug abuse, which involves reflections on drug commodification, problems arising from the criminalization and from the labor market. Contemporary values and difficulties both family and school have come up against in the socialization process of young people were also addressed. In this sense, care was seen in composing discourses that do not blame the users. Preference is given to an attitude of understanding and dialogue in the face of the problem situations posed. Although discourses oscillate, between the hegemonic and critical forms of capturing the problem, one can see that the more general understanding refers to the complex system of psychoactive drug production, consumption, and distribution and to the search for enhanced social solutions for the issue. The social practices that are developed, however, showed the absence of public policies to face the matter.

Keywords assessment of health programs and projects; education; drug users; youth. 


\section{Introdução}

Estudos avaliativos de ações e programas na interface educação-saúde são escassos, representando ausência de construção histórica consistente de avaliação, seja porque a formação dos trabalhadores de saúde traz poucos elementos de formação educacional, seja porque os estudos na área da avaliação de aprendizagem enfocam sobretudo o ensino formal, a partir do contexto escolar (Machado et al., 2008).

São bastante claras as fragilidades das políticas públicas voltadas para a área de educação sobre drogas no Brasil, sendo possível afirmar que a descontinuidade, a insuficiência e o casuísmo dos programas têm provocado efeito perverso sobre a formação dos jovens. Quando existe, a educação sobre drogas se inscreve hegemonicamente em escolas teórico-metodológicas de caráter conservador, com estratégias de adestramento e amedrontamento que acabam por afastar os jovens e causar ceticismo (Soares e Jacobi, 2000).

Contra-hegemonicamente, encontra-se em desenvolvimento um arcabouço teórico-metodológico de natureza histórico-crítica, que se propõe a construir uma educação sobre drogas de caráter emancipatório, valendo-se de pedagogia fundamentada na perspectiva dialética (Saviani, 2003). O objetivo é pôr às claras os processos sociais envolvidos no consumo prejudicial de drogas, na expectativa de que, ao conhecer as raízes histórico-sociais das formas capitalistas de consumo, os jovens e segmentos sociais envolvidos na formação dos jovens, tenham mais elementos para engajar-se em projetos de bem comum (Soares et al., 2009).

Nesse sentido, processo educativo, realizado em 2006 na Unidade Básica de Saúde (UBS) Vila Dalva, no município de São Paulo, como parte de um projeto de extensão universitária, com trabalhadores de instituições sociais que lidam com jovens, revelou ter havido modificação substancial das concepções inicialmente indicadas pelos participantes a respeito do consumo de drogas e juventude, mostrando que os saberes trazidos por eles no início do processo, identificados com os do senso comum, se complexificaram para uma compreensão das raízes do consumo prejudicial de drogas e para a superação de práticas hegemônicas na área. Esperava-se que houvesse uma alteração qualitativa da prática social, efetivada não somente a partir do cotidiano de trabalho e vida dos envolvidos, como também através do engajamento em programas de educação nessa área (Soares et al., 2009).

O objetivo deste artigo é analisar como os conhecimentos sobre consumo de drogas e juventude foram incorporados às práticas sociais dos participantes desse projeto educativo, decorridos três anos do seu desenvolvimento.

Dessa forma, coerentemente, neste trabalho tomou-se como referência fundamentos da avaliação emancipatória, conforme proposta por Saul (2006). Trata-se de processo, inscrito na vertente político-pedagógica emancipatória, 
que objetiva avaliar programas educacionais ou sociais a partir de critérios qualitativos que envolvem análise aprofundada da realidade pesquisada acionando processos de reflexão, sobre o objeto em avaliação, por parte dos envolvidos, colocados na condição de interlocutores.

\section{Procedimentos metodológicos}

Decorridos três anos de sua realização, dos 28 participantes do processo educativo, apenas 13 foram localizados e se voluntariaram para participar desta etapa do projeto. Foi utilizado roteiro previamente estruturado, com perguntas 5 abertas sobre os temas discutidos e estratégias utilizadas durante as oficinas, sobre a contribuição das mesmas para o desenvolvimento pessoal e profissional e a análise de situações envolvendo usuários de drogas, que exigissem posicionamento do entrevistado a respeito da temática.

As entrevistas, marcadas antecipadamente, foram gravadas e transcritas. A maior parte ocorreu na própria UBS Vila Dalva, local de realização do processo educativo, em 2006. O roteiro de entrevista valeu-se dos ensinamentos de outros estudos educativos (Conill e Scherer, 2003; Ribeiro, Günther, Araújo, 2003).

No pressuposto de que as diferentes práxis sociais podem não somente reproduzir a ideologia dominante, mas, ao contrário, apoiar os indivíduos no processo de compreensão da realidade, este trabalho procurou analisar os resultados de acordo com a categoria práxis, compreendida como prática social, a partir de Vàzquez (1977), que destaca que, além do trabalho, a sociedade é crivada por outras modalidades de práxis provenientes da interação entre os homens, e de Lukács, que discute como essas práxis, que não operam a transformação material da natureza, podem ser contraideológicas.

(...) um artista (...) em certas circunstâncias, quando sua práxis artística confrontada com a realidade, pode despojar-se do mundo de seus preconceitos, e captar corretamente a realidade tal como essa se apresenta em sua autenticidade e profundidade. Pode fazê-lo em certas circunstâncias, mas não necessariamente (Lukács, 1979, p. 138).

O estudo é parte de um projeto de extensão universitária, desenvolvido no departamento de Enfermagem em Saúde Coletiva, com o apoio da PróReitoria de Extensão Universitária da USP. Era de natureza qualitativa e partiu da compreensão de que, como os discursos dos sujeitos sociais se formam no curso da sociabilidade, é necessário um método de exposição da realidade que possa tanto quanto possível expressar verdadeiramente a dinamicidade do processo. 


\section{Resultados}

O Quadro 1 mostra dados de identificação dos participantes. Verifica-se que a maioria dos respondentes era mulher e trabalhava na UBS Vila Dalva, local de desenvolvimento do processo educativo. Somente um profissional ocupava função que exigia ensino de terceiro grau; os demais eram agentes comunitários de saúde, auxiliares de enfermagem, auxiliares técnicos administrativos. Três trabalhadores haviam mudado de atividade ou de trabalho: um deixou o trabalho como oficial técnico administrativo para ser estudante de graduação, bolsista de Iniciação Científica; uma passou de agente comunitária de saúde para auxiliar técnico administrativo; e uma passou de diretora de instituição infantil para pesquisadora.

Quadro 1

Perfil dos trabalhadores que participaram da avaliação, São Paulo, 2009.

\begin{tabular}{|c|c|c|c|c|}
\hline Sexo & Idade & Escolaridade & Instituição atual & Função atual \\
\hline $\mathrm{F}$ & 52 & Cursando supletivo (ensino médio) & UBS Vila Dalva & ACS - PSF \\
\hline $\mathrm{F}$ & 35 & Ensino médio completo & UBS Vila Dalva & ACS - PSF \\
\hline $\mathrm{F}$ & 44 & Cursando supletivo (ensino médio) & UBS Vila Dalva & ACS - PSF \\
\hline $\mathrm{F}$ & 27 & Superior incompleto & UBS Vila Dalva & Oficial administrativo \\
\hline $\mathrm{F}$ & 50 & Ensino médio completo & $\begin{array}{c}\text { UBS Vila Dalva e Hospital } \\
\text { Universitário }\end{array}$ & $\begin{array}{l}\text { Técnico e auxiliar de } \\
\text { enfermagem }\end{array}$ \\
\hline M & 25 & Cursando nível superior (pedagogia) & Faculdade de Educação da USP & Estudante \\
\hline $\mathrm{F}$ & 32 & Ensino médio completo & UBS Vila Dalva & Oficial administrativo \\
\hline $\mathrm{F}$ & 32 & Cursando nível superior (enfermagem) & UBS Vila Dalva & $\begin{array}{c}\text { Auxiliar de } \\
\text { enfermagem - PSF }\end{array}$ \\
\hline M & 27 & $\begin{array}{l}\text { Superior completo (enfermagem) - } \\
\text { cursando Especialização em Fisiologia } \\
\text { Humana }\end{array}$ & UBS Vila Dalva & $\begin{array}{c}\text { Auxiliar de } \\
\text { enfermagem - PSF }\end{array}$ \\
\hline $\mathrm{F}$ & 56 & Ensino médio completo & UBS Vila Dalva & $\begin{array}{c}\text { ACS (2006) e Auxiliar } \\
\text { técnico administrativo } \\
\text { (2009) }\end{array}$ \\
\hline
\end{tabular}


Continuação - Quadro 1

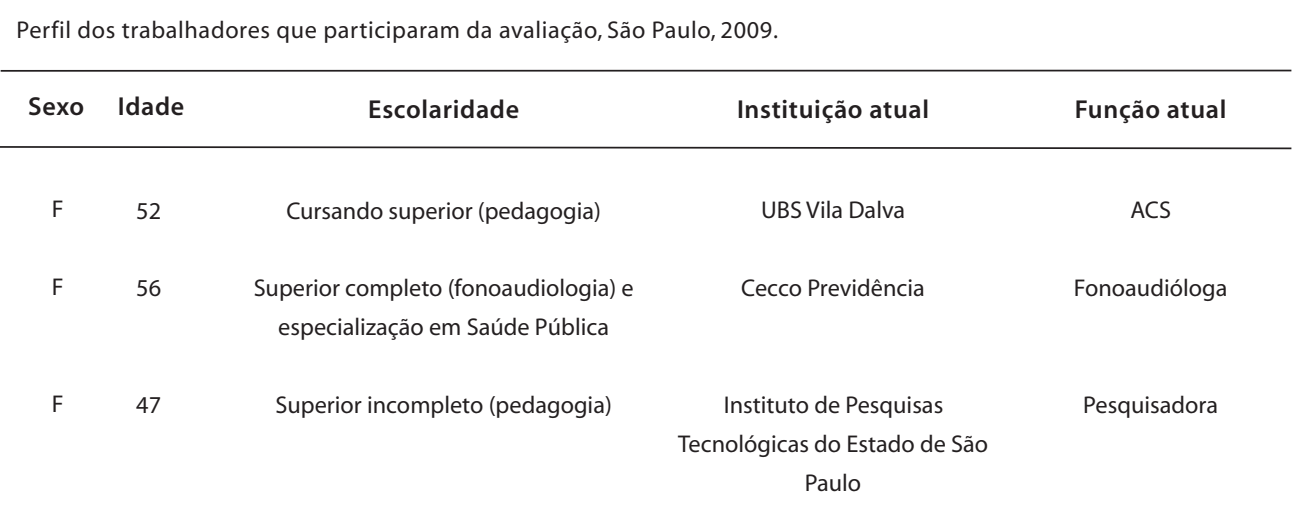

Fonte: Os autores.

\section{As práxis sociais dos interlocutores}

O conteúdo das entrevistas mostrou significados que podem ser divididos em três temas principais: complexidade da rede de causalidade imbricada no consumo de drogas; valores contemporâneos e dificuldades da família e escola na socialização dos jovens; e prática de compreensão e diálogo, diante de situações problemáticas.

\section{Compreensão da rede de causalidade do consumo de drogas: para além da culpabilização do indivíduo}

Os interlocutores entrevistados expressaram a apreensão das raízes do envolvimento com as drogas, tanto na dimensão da produção do produto quanto na sua distribuição - o comércio (legal ou ilegal) e o consumo na contemporaneidade. A análise da causalidade do envolvimento com drogas, na contemporaneidade, fundamentou-se na compreensão da substância como mercadoria, rentável para quem a produz e altamente rentável para quem a comercializa. Foi também verbalizada a compreensão do tráfico de drogas como mercado de trabalho que, para a população recrutada para essa atividade, remunera e emprega mais do que o mercado legal. Parte dessa análise pode ser depreendida nos excertos das entrevistas, descritos abaixo.

O governo não oferece subsídio para os agricultores, então os traficantes vão, os grandes cartéis, e oferecem coisas maiores para eles, para que eles plantem cocaína. Então acabam até deixando de plantar a agricultura de consumo, tipo arroz, feijão, soja, essas coisas, e plantam cocaína porque têm mais valor no mercado essas 
coisas. (...) Foi o cara que plantou, que foi explorado pelo traficante, pelo poderoso que nem aparece, você não sabe onde ele está e quem ele é. Então, por que você compra? Eu sei porque eu sei que é dessa forma. Mesma coisa é o cigarro, eu sei. $\mathrm{Eu}$, quando era garota, tantos amigos eu tinha no meio e eu não aprendi a fumar, porque eu sempre tentei entender que se o cigarro... as grandes empresas de cigarro tá na televisão. Você está vendo como eles são poderosos, está na televisão. Não é nenhum tráfico ilegal, né? Um comércio ilegal, e você sabe quem é que você está implicando, então por que você compra cigarro? Mas, enfim, o mundo é assim e você não vai poder mudar. (...) Uma coisa que me chamou muito a atenção foi isso, que a partir disso nasceu o esquadrão (sic) vermelho no Rio de Janeiro, a partir da articulação deles com (...) os presos políticos, eles não tinham o conhecimento daquilo, aquilo, não sei, aquilo me marcou, porque eles aprenderam a articular e montaram até o Comando Vermelho por conta do conhecimento que eles adquiriram junto com os presos políticos, porque os presos políticos não tinham (...) não era essa ideia, só que eles juntos adquiriram conhecimento, junto com o pessoal que eram os presos políticos da época. E o que eu me lembro também é que eles [policiais] iam para as favelas e davam tiro para todo o lado no pessoal, né? As pessoas até escondiam o pessoal do Comando Vermelho, porque como até hoje o pessoal mantém respeito e protege o pessoal mais pobre das favelas, não é? E aí você vê nitidamente isso aqui na rua em que eu trabalho, eu presencio isso todos os dias, que a comunidade se sente protegida com eles, entendeu? Então existe uma coisa velada ali, que só você estando ali pra perceber (E1).

Uma coisa que foi muito forte, que eu até já conversei bastante sobre isso de novo. (...) elas estavam explicando como que funcionava a rede mundial de comércio de drogas, como entra no Brasil, chegava na Europa, nos Estados Unidos e tudo mais. E aí ficou um pouco forte, eu fico me questionando sobre a situação no Brasil, é intensa, né? Ficou forte, então aparentemente o acesso é tão fácil que as pessoas podem usar em qualquer lugar. Daí a gente fazia o questionamento se o acesso é tão fácil e se vê tantas pessoas usando drogas, se existiria a possibilidade de não usar drogas, tipo de não ser (...) de ter uma relação sua de não usar. A gente estava nesse questionamento, se existe alguma coisa determinista social que faz, como se fosse um mecanismo social, que faz com que você utilize drogas, várias coisas. O seu papel nesse mecanismo social é tratado, usar drogas ou não usar drogas ou se poderia existir algum jeito que pudesse escolher não se envolver com essas coisas (E6).

(...) não tem emprego, então vai vender droga, e é muito mais fácil ganhar mais dinheiro vendendo droga do que se estar trabalhando o mês inteiro e ganhar $\mathrm{R} \$ 500,00$, sendo que você ganha $\mathrm{R} \$ 500,00$ em um dia vendendo drogas... Então você tem tênis melhor, roupa melhor, o consumo do jovem é esse, é roupa e tênis, é isso... Pode ser uma válvula de escape, pode ser não, é uma válvula de escape 
para ele, não é? A própria situação de vida deles, desestrutura, não tem lazer, porque aqui na região não tem lazer nenhum, lazer é usar droga e ganhar dinheiro fácil, ter roupas e tênis bom e caro e não trabalhar o mês inteiro para ganhar pouco. Os jovens são totalmente diferentes, igual eu estou falando para você que, em relação a antigamente, eles entravam na droga um pouco mais tarde, então, quer dizer, os jovens de 13 ou 14 anos já estão velhos para estar nas drogas, geralmente estão entrando com 8 ou 10 anos. Então, 14 anos já tem uma experiência, vamos dizer assim, experiência com drogas, é por isso que também tem muitas grávidas (...) porque tem situações que as meninas quando viciam elas têm que vender o próprio corpo para consumir drogas e isso também pode ocasionar doenças sexualmente transmissíveis (...) gravidez e muitos casos de mãe solteira em relação a antigamente. Antigamente, com 13, 14 anos, a gente jogava futebol, ia se divertir com alguma coisa, brincadeira de rua, hoje não, fez 14 anos, está namorando, tão com filho, vendendo drogas, é toda uma experiência, vamos dizer assim, uma maturidade maior (E9).

O filme [História de uma guerra particular] é o mais marcante. Olha, o que remete esse filme é assim... é o que acontece em qualquer favela, não tem o poder público, então é ali que cresce o poder do marginal, porque ali a pessoa não tem emprego, a pessoa não tem educação, a pessoa não tem saúde e a necessidade da pessoa, no próprio filme, mostrou que, às vezes, a minha avó está precisando de remédio, minha mãe está precisando de remédio, então ele vai lá no dono do pedaço e pede o remédio, pede a cesta básica e ele dá... E ali você vai entrando por causa da necessidade, você entra nas drogas... Então eu acho que a falta de condições do brasileiro, das pessoas que habitam nesse lugar assim, numa favela, é porque não tem emprego para poder alugar uma casa decente e viver num lugar decente. Já mora ali porque está excluído, está desempregado, e aí vai afundando cada vez mais. Eu não quero dizer também que todas as pessoas que moram numa favela estão nas drogas, que estão incluídas nisso, mas eu acho que a necessidade leva também as pessoas... Às vezes elas não querem, mas por causa da necessidade (...). É um mercado de trabalho mesmo, é isso que estávamos comentando, a pessoa, até a C. sempre fala de um caso da área dela que ela convidou para trabalhar no mercadinho e ele falou: “Ah! vou ganhar R\$ 450,00 por mês e eu ganho R\$ 400,00 por semana." Então, não quis o trabalho que ela ofereceu. O jovem, que ele era aviãozinho, o que aconteceu? Ele já está preso... faz um ano que já está preso. (...) (E11).

Vamos sair da Vila Dalva que é aquela vilazinha lá no Butantã... e aí a gente pega um universo a nível internacional e como é o tráfico a nível macro, como é que é meio assustador você ver que as duas grandes empresas [sic] mundiais que mais faturam neste planeta são os armamentos e as drogas... Então isso dá um certo 'assustamento', às vezes para mim até um pouco de impotência... que duro, que forte isso tudo, então, assim, algumas apostilas... não é que eu desconhecia isso, 
acompanha até de uma mídia geral, de jornal, de televisão etc... mas assim é bastante forte, parei um pouco para refletir um pouco nessa questão do macro, nessas duas entradas, no mercado de trabalho, a nível macro e a nível local. Muito importante a discussão a nivel local porque nós, através de experiências, acabamos percebendo que o tráfico, por exemplo, não exige carteira de trabalho para você entrar, então o teu trabalho está lá, então amanhã você vem aqui e vai fazer isso e vai ganhar $\mathrm{x}$, então são pessoas que têm uma dificuldade de acesso ao trabalho, não é que eles não querem trabalhar, eles têm uma dificuldade de acesso ao trabalho, a formação é capenga porque a educação é capenga... Tirando um pouco essa criminalização das pessoas, então são pessoas que não querem trabalhar porque não querem fazer isso, porque... Então, assim, é um mercado aberto. Não tem porta, não tem tranca, não tem aquela burocratização que (...) às vezes é necessária, mas não em demasia, então lá eles têm abertura para trabalhar, às vezes até a questão da flexibilidade de horário facilita a vida deles... eu acho que esse é um ponto para a gente até refletir, tem uma estrutura fechada, a nivel de uma estrutura até burocrática, tem uma crise de mercado de trabalho... e se tem uma crise para aqueles que têm uma formação um pouco melhor, então imagina para essas pessoas que estão numa condição mais difícil? Então entra mesmo, entra. Então acho que a gente tem que começar a mudar esse olhar e compreender, mesmo as festas que o tráfico está junto, que são os tais pancadão que eles falam, que é o consumo como escape, que está lá a polícia, os traficantes, então a gente precisa ter uma compreensão, eu diria até uma palavra desgastada, um palavrão, que é humanizadora.... que é isso... Tira assim essa coisa dos chavões que às vezes a gente costuma colocar naquela comunidade que tem dificuldades de habitação, de saúde, de acesso à saúde, ao emprego, apesar de todas as conquistas ainda é difícil, até a entrada no posto de saúde, então tem que entender. Às vezes as coisas no tráfico, eles abrem as portas mais rápido (E12).

\section{Valores contemporâneos e dificuldades da família e escola na socialização dos jovens}

Entre os interlocutores entrevistados, houve também a compreensão de que nem sempre o consumo de substâncias psicoativas significa caminho para a dependência ou para a marginalidade, como expresso no excerto El, que exemplifica o consumo de droga como opção, num contexto de sociabilidade. O mesmo excerto mostra a compreensão de que em outro contexto, no da falta de perspectiva, ao qual acrescentaríamos a inserção de classe social, provavelmente o envolvimento com as drogas pode significar uma sociabilidade de outro tipo - a entrada para o tráfico. Os demais excertos de entrevistas a seguir reiteram que a entrada para esse trabalho - o tráfico - também significa ampliar para esses jovens as possibilidades de consumo de artigos 
de luxo, consumo esse inviável em inserção em outro trabalho, uma vez que até mesmo a escola, agência encarregada da facilitação da entrada no mercado de trabalho, pela via da formação e qualificação para o trabalho, não tem cumprido seu papel, como mostra o excerto Ell. Essa compreensão permitiu aos trabalhadores desfocar dos jovens, individualmente, a culpabilização do envolvimento com as drogas, como se esse envolvimento fosse uma opção entre tantas outras que eles poderiam ter.

Os estudantes da USP, a gente sabe, por exemplo, de tantos estudantes que usam droga. Você sabe que os estudantes da USP usam droga! Eles não estão à margem da sociedade, eles são estudantes, estão se formando, vão ser doutores, então o que é isso? É porque eles querem usar drogas, eles acham legal, não é porque eles têm uma vida errada, não é porque eles estão mal com a família, não é por isso, é porque eles acham legal. (...) [Ao mesmo tempo], que tipo de vida que leva uma família que não tem estrutura para orientação, muitas vezes a mãe não quer mais nem saber de orientar, porque já está cheia mesmo de problemas. Então o filho vai ficar cada vai mais afastado, e é quando o traficante leva o filho para junto deles, porque a pessoa vai se sentindo apoiada junto com o traficante, entendeu? A gente ouve: "Olha esse aqui sou eu amanhã." Entendeu? Então, a grande questão, o cara fala: esses aqui sou eu amanhã, tô criando pra me substituir amanhã. Essa frase está aqui em mim! Porque cadê os pais? Cadê a família? É círculo vicioso, nunca vai diminuir a situação (E1).

E aí o outro me falou que, assim, desde pequeno ele passou por conflitos dentro de casa, só que quando a gente é pequena, a gente não entende o que se passa, você vai crescendo e vendo aquelas situações. E ele me falou, assim, que via, quando começou a ficar adolescente, um jeito de fugir dessas horas, porque ele não podia tomar partido nem do lado do pai e nem do lado da mãe, ele gosta dos dois. Então o que ele fazia, ele ia com os amigos, e os amigos falavam assim: "Ah, não! Dá uma pitadinha só que você vai ver que daqui a pouco você esquece." Só que aí ele dava a pitadinha, esquecia no momento, na hora, a noite toda, no outro dia ele voltava na casa e a história continuava a mesma, e aí ele viu que não estava adiantando nada, mas continuava insistindo, toda vez que tinha alguma com ele mesmo, às vezes nem com os pais, com ele mesmo, ele chegava e ia com os amigos para poder usar a droga (E4).

Eu fiz educação de jovem e adulto (EJA), no Samuel Klabin [escola pública da região], e eu via como que o ensino é fraco, para entrar numa faculdade pública, entendeu? Como que as pessoas sabem realmente que ali não vai levar a lugar nenhum, elas já sabem. Eu via os comentários "eu nunca vou conseguir", via os comentários. E tinha pessoa que falava assim "o que eu fazer na faculdade?" Os jovens mesmo, a maioria, não levantam a mão, só um ou outro que pensa em fazer 
uma faculdade, porque eles sabem ali que com aquele ensino não vão conseguir entrar, vão ter que batalhar muito... Eles não têm perspectiva de vida, a maioria a gente via nos grupinhos, que fala logo isso abertamente, "ah, porque eu fumo!" Olha, eu fiz isso e fiz aquilo, eles falavam abertamente na sala de aula, não tinham nem vergonha, sabe? Para eles é uma coisa normal. Então eu via a falta de perspectiva em relação ao ensino, então eles acham que não vão chegar a lugar nenhum. Isso que eu percebia, e realmente não tem mesmo, eu vi que realmente [o ensino] é muito fraco, entendeu? (...). Eu acho que essa coisa mesmo da falta de perspectiva e essa crise toda que está o país só tende mesmo a piorar as coisas, entendeu? (E11).

\section{Prática de compreensão e diálogo diante das situações-problema colocadas: usuários são pessoas normais}

Os fragmentos das entrevistas, descritos abaixo, mostraram que após as oficinas os participantes tiveram oportunidade de refletir sobre a humanidade do usuário de drogas, desmistificando assim a associação entre o usuário de drogas e a impossibilidade de aproximação e contato, o que parece ter permitido aos trabalhadores de saúde uma aproximação com as pessoas envolvidas de alguma forma com substâncias psicoativas. Essa reflexão e mudança de conduta se deveram à possibilidade de examinar a causalidade do envolvimento com as drogas numa perspectiva mais ampla, que envolve a macroestrutura econômica.

Então eu compreendo que ela [pessoa que consome droga] não é diferente porque usa droga; ela poderia até não usar droga e ser daquela forma. Mas eu acho que eu passei a compreender depois que conheci uma pessoa (...) que fuma maconha, né? Mas é uma pessoa que leva sua vida normal, estuda, trabalha, que tem uma vida social, que não é diferente do que a gente acha que é normal, o que é normal eu também não sei! Né? O que é normal? Mas, assim, a gente acha que as pessoas que vivem à margem da sociedade, o pessoal que trafica, que é bandido, vivem à margem da sociedade e, no entanto, tem gente que usa droga e não vive à margem da sociedade, então o que é isso? É muita coisa, é muita piração para se pensar (...) (E1).

E mesmo assim eu acho que qualquer ser humano é digno de ser tratado com respeito, independente da condição de vida dele, se ele é viciado, se ele deixa de ser, a gente não tem que julgar, não é? Assim, eu nunca fui de julgar, uma coisa que eu aprendi muito é que nunca se deve julgar as pessoas, que nem nesse trabalho... pelo que você vê, cada um tem uma história de vida diferente, então isso marcou, para mim isso marcou, nunca deve julgar porque cada um tem um estilo de vida diferente, você não sabe o que essa pessoa traz, tanto que isso para mim marcou bastante (E10). 
Eu acho que, com o tempo (...), se é muito cheio de preconceito, quando você não tem esse conhecimento, aí você vai jogando muito, ah!, tipo assim, é menina fácil, é isso, é aquilo, mas quando você começa a entender o meio em que ela vive e como é a cabeça da pessoa, é aí que se começa a entender a pessoa. Não é que você vai ficar assim já julgando, mas aí você vai aceitando as pessoas, tanto é que eu fui fazer uma visita da dengue, um trabalho lá na favela, e aí encontrei uma menina que eu fiquei sabendo, e justamente foi falado também um dos exemplos dessas oficinas, aí encontrei com ela, e comecei a conversar com ela, eu já sabia que era ela (...), a E. já tinha me falado: “Ah!, é essa daí, é aquela que eu comentei lá, ela é a esposa do traficante e o traficante estava preso, porque antes ele era o dono do pedaço aí." Aí eu fui lá conversar com ela, fui na casa dela, dei explicações sobre a dengue (...), ela atendeu a gente super bem, eu achei ela tão legal, mas se fosse antes (...), antes de ser agente [comunitário de saúde], eu já iria ficar meio assim, talvez nem quisesse conversar com a pessoa, mas agora não, a gente entende, atendeu a gente super bem. As oficinas ajudaram porque na verdade, que eu lembre, foi a capacitação mais completa que eu tive, a gente já teve um trabalho mais de falar sobre as drogas, assim as coisas mais técnicas, mas não existia um trabalho do que se pode fazer, como [teve] nas oficinas, de mostrar exemplos, de falar sobre os casos, não houve. Então eu acho que para mim, eu comecei a entender mais a cabeça das pessoas, porque eu via pelo meu lado de, assim, de me afastar das pessoas que eram assim. Nas oficinas a gente procurava entender o porquê que a pessoa é assim, porque é um ser humano como a gente, só que a vida dela, não sei dizer, ah!, não teve opção, porque eu acho que todo mundo, de certa forma, tem a opção na vida, de escolha, e ela escolheu, mas a gente tem que entender que há um passado que a levou para aquela escolha, não é verdade? Na vida a gente aprende a ser muito aquela coisinha, é só isso: ou é só do bem ou é só do mal. (...) Essa educação, só existe isso, mas a gente vai conhecendo as pessoas e vendo as histórias e vai vendo que não é só isso, o ser humano é cada um, é diferente e tem uma história por trás, e isso é que é o interessante de se ver, tem uma história por trás, e que todos são seres humanos, a pessoa pode mudar em qualquer hora, uma pessoa pode mudar. Pra você ver, ela estava lá cuidando dos filhos, tinha um menino (...) muito bonitinho, muito engraçadinho. Nossa! Como eu me lembro dela, ela atendeu a gente muito bem, falamos sobre a dengue, falamos sobre a casa dela, falamos sobre o esgoto que passa na frente da casa dela e o menininho dela brincando na frente do esgoto... e falando: "Ah!, por que o governo não vem aqui, o governo não faz isso, entendeu?" E eu falei nossa! Que interessante essa pessoa, isso ficou na minha cabeça. Pra você ver, é um ser humano como outro qualquer, que tem seus desejos e necessidades, que precisa de apoio, que precisa de ajuda. Eu vejo assim, é muito complicado porque as pessoas têm os dois lados, uma hora está ali conversando com a pessoa superlegal e por outro lado a outra pessoa pode de repente matar uma outra pessoa (E11). 
Esse conhecimento das oficinas me ajudou a chegar mais perto das pessoas, a entender, a conversar, a ter mais amizade porque antes eu ficava mais distante, tinha até medo. Então, ficava assim: "Aquela ali, não sabia como conversar", não entendia. Agora eu já consigo [entender] que é uma pessoa que eu posso ter um relacionamento, posso conversar, posso ter mais amizade, se ela está aberta... O que ela precisar falar comigo eu procuro fazer o melhor possível, mas assim... não chegou nenhum caso, assim, de chegar e falar sobre esse assunto, não (E11).

\section{Ausência de políticas programáticas, inclusive no Programa Saúde da Família (PSF): soluções individuais?}

Note-se que, após as oficinas, os participantes trabalhadores em serviço de saúde perceberam a necessidade de práticas direcionadas aos jovens, para além da perspectiva da atenção individual, inclusive foram citadas as de âmbito intersetorial - como exemplifica o fragmento E3. Foi também manifestada a percepção do pouco investimento da atenção básica, inclusive no PSF, tanto na operacionalização de práticas quanto na formação de trabalhadores para o aperfeiçoamento da atenção para esse segmento juvenil, expresso nos fragmentos E9 e El1.

Eu tenho vontade, com uma ajuda de alguém, um psicólogo, alguém que estivesse disponível, de fazer grupos com os jovens. A minha vontade é de grupo com jovens e ter uma orientação, né? Para eles terem mais uma clareza na mente; de ter lugar pra gente encaminhar eles, atividades, esporte, para eles não ficarem muito envolvidos. Porque eles não têm pra onde ir e ficam aqui na rua empinando pipa ali, andando sempre junto, aí os mais velhos ali começam a envolver eles, né? Diz a eles que vão conseguir dinheiro mais fácil, vão ganhar dinheiro, então é isso. Tinha vontade, assim, de ter esporte pra quando a gente encaminhar (E3).

(...) Aonde eu moro tem sim, tem inclusive na idade nova, 12 anos, por exemplo, com 14 anos já está numa experiência porque com 12 anos já está jogando futebol, com aquelas brincadeiras de rua e com 14 anos já está diferente, já fica na esquina de boné baixo, só olhando o movimento, e é isso, tem uma observação maior com tudo, desconfiança de tudo, na verdade eu tenho que enxergar de uma outra forma porque eles infelizmente não ouvem muito a gente, então a gente tem que tentar buscar métodos mais aperfeiçoados porque o jovem mesmo não procura o centro de saúde, e mesmo quando vem com o excesso de droga, vem para passar porque está passando mal e vindo no serviço e aí você descobre que está usando droga, mas o que você pode fazer não é [dizer]: pare de usar, não pode falar pare de usar porque é uma opção dele, então você tem que ver e dar dois caminhos para ele e ver 
(...) qual é a situação que ele acha correto seguir - o lado de usar drogas é esse e o lado de não usar drogas é esse, então está dando dois caminhos para ele escolher... (E9).

Então eu acho que o governo realmente não está investindo nisso, [tem] muitos jovens entrando nisso, [é] muito fácil de entrar, de ganhar e o governo está fazendo quase nada, acho que está fazendo o mínimo. Na saúde, o trabalho mesmo da prefeitura, eu nunca vi trabalho nenhum a esse respeito, nem quando eu estava no orçamento participativo não tinha proposta para isso, sabe? Eu acho que eles estão deixando os traficantes tomarem conta mesmo, não tem boa vontade do governo, eles fazem o mínimo para dizer que fez. Tem um trabalhinho aqui, tem uma casa aqui, e não dá conta de tudo, e é um trabalho muito difícil, a pessoa tem que querer mesmo ajudar porque senão ela não tem estrutura... Eu acho que devia ter mais empenho do governo (E11).

(...) o PSF relacionado às drogas é muito limitado, não tem nenhum trabalho, não temos nenhum projeto em relação a isso, entendeu? Existe na minha área uma praça em que à tarde eu vejo os jovens que geralmente não são da minha área mesmo, da minha rua, que vêm ali para ficar conversando e durante a tarde assim, normal, às vezes à noite também na praça. Mas a gente não tem contato assim, a gente só trabalha com pessoas que nos procuram, entendeu? O PSF é bem limitado nessa coisa, nas drogas, só trabalhamos com pessoas que nos procuram, é assim... Esse pessoal já até mudou, era o J. o [médico] residente que estava atendendo um rapaz da minha área, então ele encaminhava para outros lugares. A gente não faz aqui, ficam as duas coisas, até atendendo e encaminhando para outros lugares, não tem nenhum trabalho. Na verdade assim não, o conhecimento que a gente tem é mais de lidar com as pessoas até no sentido de ter confiança, de conversar (...), mas de falar diretamente sobre esse assunto, ninguém ainda da minha área deu liberdade para isso (...) (E11).

\section{Discussão}

A possibilidade de análise da causalidade do envolvimento com as drogas é determinada pela perspectiva teórica que se elege.

Assim, hegemonicamente, a área da saúde tem optado pela análise que toma a temática das drogas da perspectiva do sujeito usuário, e o faz com os conhecimentos advindos da psicologia e da psiquiatria, para classificar o tipo de uso e de usuário e para tratamento dos problemas advindos dessa relação usuário e uso de substâncias psicoativas, especialmente quando a consequência é a dependência (Soares, Campos, 2009).

Nessa perspectiva, os usuários ou os dependentes de drogas são tratados como desviantes ou, na melhor das hipóteses, como doentes (Velho, 
1974), o que determina que ocupem, na representação dos trabalhadores da saúde, um lugar que dificulta, e muitas vezes impossibilita, a aproximação e a escuta de suas necessidades.

No entanto, para compreender a complexidade das raízes do envolvimento com as drogas, tanto no que diz respeito à produção quanto à distribuição e ao consumo, buscou-se nas Ciências Sociais um corpo de conhecimentos que pudesse empreender uma análise mais ampla do que aquela restrita a causalidades localizadas no indivíduo ou na substância propriamente dita (Soares, 2007). Uma tal perspectiva contra-hegemônica desinternaliza (Mészáros, 2005) valores atinentes à lógica invertida que retira das formas capitalistas de produzir e consumir o ônus pelas formas compulsivas atuais de se relacionar com as drogas. Essa perspectiva vem sendo alicerçada pela Saúde Coletiva (Soares, 2007).

Essa perspectiva teórica busca compreender a inflexão que sofreu o consumo de drogas a partir da consolidação do capitalismo, que imprimiu às drogas a característica de mercadoria e aderiu ao consumo a possibilidade de lucro ao distribuidor, para além do prazer individual do consumidor (Soares, 2007).

Assim, com a desvalorização da agricultura e a inviabilidade de manutenção de vida digna de agricultores de países de capitalismo periférico, especialmente na América do Sul, a alternativa viável foi a 'narcorreciclagem' - troca de culturas voltadas à produção de alimentos por culturas de coca como matéria-prima para a produção de substâncias psicoativas para o tráfico internacional (Soares e Campos, 2009).

Como resposta ao desemprego estrutural contemporâneo, à precarização dos vínculos trabalhistas e do trabalho em si, a partir da reestruturação do trabalho determinada pela estratégia neoliberal, e como possibilidade de encaixe como consumidores de produtos de luxo, um conjunto expressivo de jovens das periferias vem sendo recrutado para o mercado de trabalho do tráfico (Kaplan, 1997), ao mesmo tempo em que muitos chefes de família têm ficado alijados da possibilidade de manutenção da sobrevivência da família (Soares, 2007).

O uso de substâncias psicoativas, lícitas ou ilícitas, é muito oportuno como resposta a essas angústias e às necessidades impressas pela sociedade de mercado - estímulo para o consumo indiscriminado e enaltecimento do prazer imediato (Soares e Campos, 2009).

Os interlocutores entrevistados demonstraram apreensão dessa explicação para o envolvimento com as drogas, o que favoreceu a possibilidade de aproximação com a temática, antes evitada. Percebe-se dessa forma que a educação, que traz elementos de 'formação científica, técnica e política', pode proporcionar uma compreensão antagônica (Frigotto, 2009) àquela alastrada pela ideologia dominante que inverte os valores, colocando as drogas 
como causa dos problemas relativos ao consumo e os jovens como culpados pelos problemas advindos do consumo.

Por outro lado, os entrevistados sinalizaram a necessidade de implementação de ações voltadas aos jovens. Até mesmo os trabalhadores da unidade básica de saúde que têm suas ações organizadas segundo a Estratégia de Saúde da Família referiram a ausência de ações que tomem como objeto o consumo de drogas e a juventude.

Provavelmente essa constatação é reflexo da apropriação, ou melhor, da falta dela, pelas políticas públicas.

No Brasil, a juventude só foi reconhecida como detentora de direitos com a aprovação do Estatuto da Criança e do Adolescente (ECA), no mesmo contexto social que promoveu a universalização do direito à saúde, através do Sistema Único de Saúde (SUS), na década de 1990.

No entanto, a universalização das políticas públicas dirigidas a esse segmento etário não se efetivou, limitada, por um lado, pelo recorte etário excluía os que estivessem fora da faixa entre 12 e 18 anos incompletos - e, por outro, pelo critério que incluía apenas jovens em processo de exclusão ou risco (Sposito e Carrano, 2003).

No entanto, a situação de precarização das condições de vida de parcela crescente de jovens e do aumento do número de mortes violentas e envolvimento, como tráfico de drogas, nessa mesma década de 1990, obrigou o Estado a estabelecer políticas voltadas a esse segmento, ainda que focalizadas aos jovens pobres (Sposito e Carrano, 2003).

O Estado brasileiro passou então a introduzir políticas compensatórias para esses jovens, ao mesmo tempo em que autorizava o mercado a explorar direitos sociais, como os de saúde e educação, incentivando o acesso a serviços privados, regidos pelas leis do mercado (Soares, 2009).

Pode-se afirmar que as políticas públicas voltadas ao segmento juvenil no Brasil ainda tomam a juventude como período de transição para a vida adulta. As ações nesse caso são as advindas principalmente da área da educação, com a intencionalidade de prepará-los para a vida adulta, na qual a marca esperada é a da estabilidade. Contudo, para jovens de classes sociais com poucas possibilidades de acesso a bens materiais e de cidadania, essa etapa é tomada como problemática, pelo risco que esses jovens representam de desenvolver comportamentos desviantes ou delinquentes (Aquino, 2009). Para esses jovens, as ações são focalizadas em oficinas e alguns projetos de esportes, com o intuito de mantê-los de 'mãos ocupadas', nos períodos que estão fora da escola de ensino formal (Abramo, 1997).

Embora sejam inegáveis os avanços, as políticas públicas advindas do governo federal ainda continuam focalizadas para a população classificada como de 'risco social', destinadas a incentivar a elevação da escolaridade por meio de pagamento de bolsa, mais na perspectiva de políticas 
emergenciais e menos na intencionalidade de políticas universalizantes (Silva e Andrade, 2009).

Não é diferente na área da saúde. A população juvenil, alvo da atenção básica, também é a moradora das periferias, e as ações são pontuais - vacinação, tratamento de algumas doenças, teste de gravidez e métodos contraceptivos (preservativos e pílulas anticoncepcionais) (Amarante e Soares, 2009).

Estudo desenvolvido no âmbito da atenção básica do município de São Paulo constatou que, dentre as poucas diretrizes disponíveis na Secretaria Municipal de Saúde, o documento norteador de ações para esse segmento etário atestava

focalização da atenção à saúde do jovem em vulnerabilidades - dificuldades nas relações familiares, uso de drogas lícitas e/ou ilícitas, início da vida sexual, DST/Aids, gravidez, aborto e suas consequências, exclusão social, risco de suicídio, acidentes de trânsito, violência doméstica e sexual (Amarante e Soares, 2009).

Resultados desse estudo também mostraram que os trabalhadores desses serviços de saúde, quando desenvolvem atividades voltadas para os jovens, na maioria das vezes o fazem por iniciativa própria e sinalizaram com a necessidade de capacitação para o trabalho (Amarante e Soares, 2009), especialmente quando o tema em questão é o consumo de drogas.

Reiterando esses resultados, os entrevistados deste estudo expressaram a necessidade de desenvolvimento de ações voltadas à juventude, mas também de espaços no trabalho que viabilizem processos de reflexão e formação para o aprimoramento das práticas dirigidas a esse segmento.

Vale salientar que, munidos de uma explicação contra-hegemônica sobre a teia imbricada no consumo de pscoativos, os trabalhadores têm chance de mudar sua práxis junto aos jovens, compreendendo que

no plano da práxis atuamos numa realidade histórica que não é fruto de uma escolha de acordo com nossa vontade, mas como resultado de uma realidade produzida nas relações de força. Mas, lembra-nos Marx, são os seres humanos que produzem essa realidade e que, portanto, são eles que podem mudá-la. No processo de luta contra-hegemônica, o ponto crucial que nos desafia, na teoria e na práxis, é o de distinguir as mudanças que concorrem para alterar estruturalmente as relações sociais capitalistas daquelas que as alteram para conservar (Frigotto, 2009, p. 78).

\section{Conclusões}

A prática social dos trabalhadores envolvidos no processo educativo mostrou indicativos de que o componente teórico discutido nas oficinas per- 
maneceu e é representado a partir dos contornos próprios das formações individuais dos participantes. Sem dúvida nenhuma, para além dos conteúdos abordados, certamente reveladores da trama social mais ampla, foi marcante a vitalidade das estratégias utilizadas, notadamente a discussão de um documentário assistido conjuntamente, orientada por um roteiro de questões previamente formuladas e construção em grupos de um personagem jovem usuário de drogas.

Há indícios de que a prática social no trabalho e na vida foi amalgamando a teoria inicialmente proposta para explicar a realidade do consumo de drogas entre jovens, comprovada que ia sendo pelas experiências do cotidiano. Isso provocou um misto de potência e de frustração. Frustração, porque o problema é macrossocial e complexo; e potência, porque é possível ter uma atitude no dia-a-dia que, fiel a essa compreensão ampliada, retira do jovem em si a responsabilidade pelo consumo de drogas, colocando-a nos ombros da sociedade.

As práticas sociais desenvolvidas são também individuais e implementadas em função de situações problemáticas, que exigem do trabalhador a compreensão ampliada do problema, para além da assistência restrita apenas a conhecimentos biopsíquicos.

No entanto, não há práticas sociais sistematizadas, orientadas por programas oficiais, voltadas à juventude, especialmente na área da saúde, evidenciando-se a ausência de políticas públicas para o enfrentamento do problema. A estratégia saúde da família ou PSF, como é mais comumente referida, no que diz respeito aos jovens, continua tomando como objeto de suas ações parte da saúde reprodutiva do jovem, tratando-o particularmente como um ser capaz de 'adquirir DST e gravidez precoce'.

Dessa forma, para a implementação de práticas sociais efetivas, é imprescindível a aproximação e compreensão do problema, analisando-se o fenômeno consumo de substâncias psicoativas na contemporaneidade e os valores contemporâneos que permeiam a vida dos jovens e as suas (im)possibilidades de escolhas e decisões. 


\section{Notas}

1 Professora associada do Departamento de Enfermagem em Saúde Coletiva, Escola de Enfermagem, Universidade de São Paulo, São Paulo, Brasil. Livre docente em Enfermagem pela Escola de Enfermagem da Universidade de São Paulo. <cassiaso@usp.br> Correspondência: Universidade de São Paulo, Departamento de Enfermagem em Saúde Coletiva. Av. Dr. Enéas de Carvalho Aguiar, 419, sala 233, $2^{\circ}$ andar, Cerqueira Cesar, CEP 05403-000, São Paulo, São Paulo, Brasil, Caixa Postal 41633.

2 Professora do Departamento de Enfermagem em Saúde Coletiva, Escola de Enfermagem, Universidade de São Paulo, São Paulo, Brasil. Doutora em Enfermagem pelo Programa Interunidades Escola de Enfermagem da Universidade de São Paulo e Escola de Enfermagem de Ribeirão Preto da Universidade de São Paulo. < celiasiv@usp.br>

3 Graduanda do terceiro ano de Enfermagem, Escola de Enfermagem, Bolsista do Programa Aprender com Cultura e Extensão, Pró-Reitoria de Cultura e Extensão Universitária, Universidade de São Paulo, São Paulo, Brasil. <jsetteberto@yahoo.com.br>

4 Especialista em Laboratório de Ensino, Pesquisa e Extensão do Departamento de Enfermagem em Saúde Coletiva, Escola de Enfermagem, Universidade de São Paulo, São Paulo, Brasil. Mestre em Enfermagem pela Escola de Enfermagem da Universidade de São Paulo. <egpereira@usp.br>

5 Dentre as perguntas, destacamos as seguintes: a) Conte uma situação em que notou diferença na sua forma de lidar com os jovens com quem convive (irmão, filho, família, amigos, ou com os jovens que convive no trabalho); b) Como se colocaria nas seguintes situações: o que você faria se seu filho chegasse embriagado em casa?; o que você faria se encontrasse maconha nas coisas dele?; qual sua reação ao se deparar com um grupo de jovens na rua fumando maconha?; no fim do dia você e seus colegas de trabalho vão a um bar e uma de suas colegas conta que usa cocaína, como você reagiria? O que falaria para ela?; o que você faria se algum familiar te pedisse dinheiro emprestado para pagar dívidas com traficantes?; o que faria se algum familiar seu pedisse dinheiro emprestado para comprar bebidas ou cigarro?; o que faria se algum familiar seu pedisse dinheiro emprestado para comprar ecstasy para ir a uma festa rave?

\section{Referências}

AMARANTE, Andréa G. de Medeiros; SOARES, Cássia Baldini. Políticas públicas de saúde voltadas à adolescência e à juventude no Brasil. In: BORGES, Ana Luiza Vilela; FUJIMORI, Elizabeth (Org.). Enfermagem e a saúde do adolescente na atenção básica. Barueri: Manole, 2009. p. 42-60.

AQUINO, Luseni Maria Cordeiro. Juventude como foco das políticas públicas. In: 
CASTRO, Jorge Abrahão; AQUINO, Luseni Maria Cordeiro; ANDRADE, Carla Coelho (Org.). Juventude e politicas sociais no Brasil. Brasília: Ipea, 2009. p. 23-39.

ABRAMO, Helena Wendel. Considerações sobre a tematização social da juventude no Brasil. Revista Brasileira de Educação, Rio de Janeiro, n. 5-6, p. 25-36, 1997.

CONILL, Eleonor Minho; SCHERER, Magda D. dos Anjos. Novas estratégias em educação: avaliação da técnica 'Tribunal do Júri' na capacitação de conselheiros na área de saúde da mulher em Santa Catarina, Brasil. Cadernos de Saúde Pública, Rio de Janeiro, v. 19, n. 2, p. 525-534, 2003.

FRIGOTTO, Gaudêncio. Teoria e práxis e o antagonismo entre a formação politécnica e as relações sociais capitalistas. Trabalho, Educação e Saúde, Rio de Janeiro, v. 7, suplemento 1, p. 67-82, 2009.

KAPLAN, Morton. Tráfico de drogas, soberania estatal, seguridade nacional. Revista Sistema, n. 136, p. 43-61, 1997.

LUKÁCS, György. Ontologia do ser social: os princípios ontológicos fundamentais de Marx. Tradução de Carlos Nelson Coutinho. São Paulo: Ciências Humanas, 1979.

MACHADO, Felipe Rangel de Souza et al. Elementos para a discussão da avaliação do trabalho educativo em saúde. In: PINHEIRO, Roseni; SILVA-JR.; Aluísio Gomes; MATTOS, Ruben Araujo (Org.). Atenção básica e integralidade: contribuições para estudos de práticas avaliativas em saúde. Rio de Janeiro: Abrasco, 2008.

MÉSZÁROS, István. A educação para além do capital. São Paulo: Boitempo, 2005.

RIBEIRO, Helena; GÜNTHER, Wanda M. Risso; ARAUJO, Joyce Maria. Avaliação qualitativa e participativa de projetos: uma experiência a partir de pesquisa em educação ambiental e saneamento do meio. Saúde e Sociedade, v. 11, n. 2, p. 107-132, 2002.
SAUL, Ana Maria. Avaliação emancipatória: desafio à teoria e à prática de avaliação e reformulação de currículo. São Paulo: Cortez, 2006.

SAVIANI, Dermeval. Pedagogia históricocrítica: primeiras aproximações. 8. ed. rev. amp. Campinas, São Paulo: Autores Associados, 2003.

SILVA, Enid Rocha Andrade; ANDRADE, Carla Coelho. A política nacional de juventude: avanços e dificuldades. In: CASTRO, Jorge Abrahão; AQUINO, Luseni Maria Cordeiro; ANDRADE, Carla Coelho (Org.). Juventude e políticas sociais no Brasil. Brasília: Ipea, 2009. p. 43-69.

SOARES, Cássia Baldini. Mais que uma etapa do ciclo vital: a adolescência como um construto social. In: BORGES, Ana Luiza Vilela; FUJIMORI, Elizabeth (Org.). Enfermagem e a saúde do adolescente na atenção básica. São Paulo: Manole, 2009. p. 3-22.

O consumo de drogas como objeto de estudo na contemporaneidade. In: SOARES, Cássia Baldini. Consumo contemporâneo de drogas e juventude: a construção do objeto na perspectiva da saúde coletiva. Tese de livre-docência. São Paulo: Escola de Enfermagem, USP, 2007.

SOARES, Cássia Baldini; CAMPOS, Célia M. Sivalli. Consumo de drogas. In: BORGES, Ana Luiza Vilela; FUJIMORI, Elizabeth (Org.). Enfermagem e a saúde do adolescente na atenção básica. São Paulo: Manole, 2009. p. 436-468.

SOARES, Cássia Baldini; CAMPOS, Célia M. Sivalli; LEITE, Adriana Souza; SOUZA Cristina Lourdes Leite. Juventude e consumo de drogas: oficinas de instrumentalização de trabalhadores de instituições sociais, na perspectiva da saúde coletiva. Interface: Comunicação, Saúde e Educação, São Paulo, v. 13, n. 28, p. 189-199, 2009.

SOARES, Cássia Baldini; JACOBI, Pedro Roberto. Adolescentes, drogas e Aids: 
avaliação de um programa de prevenção escolar. Cadernos de Pesquisa, São Paulo, n. 109, p. 213-237, 2000.

SPOSITO, Marília Pontes; CARRANO, Paulo César Rodrigues. Juventude e políticas públicas no Brasil. Revista Brasileira de Educação, Rio de Janeiro, n. 24, p. 16-39, 2003.

VÀzQUEZ, Adolfo Sánchez. Filosofia da práxis. Rio de Janeiro: Paz e Terra, 1977.
VELHO, Gilberto. O estudo do comportamento desviante: a contribuição da antropologia social. In: (Org.). Desvio e divergência: uma crítica da patologia social. Rio de Janeiro: Zahar, 1974. p. 11-28.

Recebido em 11/06/2010

Aprovado em 30/08/2010 